\title{
Unequal Burden of Diabetes and Hypertension in the Adult Population of the San Juan Metropolitan Area of Puerto Rico
}

\author{
Myriam Zaydee Allende-Vigo ${ }^{1 *}$, Cynthia M. Pérez ${ }^{2}$, José J. Hernández ${ }^{3}$, Carlos R. Torres ${ }^{2}$, Yari Valle ${ }^{2}$, Ruth Rosario ${ }^{4}$ and Erick Suárez ${ }^{2}$
}

${ }^{1}$ Department of Medicine, School of Medicine, University of Puerto Rico Medical Sciences Campus, USA

${ }^{2}$ Department of Biostatistics and Epidemiology, Graduate School of Public Health, University of Puerto Rico Medical Sciences Campus, USA

${ }^{3}$ Pharmacy Practice Department, School of Pharmacy, University of Puerto Rico Medical Sciences Campus, USA

${ }^{4}$ Medical Technology Program, School of Health Professions, University of Puerto Rico Medical Sciences Campus, USA

\section{Abstract}

Objective: The study describes critical information gaps regarding diabetes, hypertension, prediabetes, prehypertension and its comorbidities in a representative sample of the Hispanic adult population living in Puerto Rico.

Research design and methods: A representative sample of non-institutionalized Puerto Ricans adults aged 18-79 years residing in the San Juan metropolitan area participated in a face-to-face interview, anthropometric measurements and blood draws. Prevalence of diabetes, hypertension, prediabetes, and prehypertension were estimated using logistic regression. Levels of awareness, treatment, adherence to medications, and control of these conditions were assessed.

Results: Of 452 participants, $15.2 \%$ had diabetes, $35.3 \%$ had pre-diabetes, $39.9 \%$ had hypertension and $44.9 \%$ had pre-hypertension. Females were more likely to have diabetes, except those aged 18-64 years. Prevalence of diabetes, pre-diabetes, hypertension and pre-hypertension increased significantly with age in both sexes. Prehypertension was more prevalent among males in all age groups. Only $35 \%$ of those diagnosed with diabetes and $52.5 \%$ of those diagnosed with hypertension were controlled on pharmacotherapy.

Conclusions: There is an unequal burden of diabetes, pre-diabetes, hypertension and pre-hypertension in Puerto Rico. The prevalence is high, increased significantly with age, and although the vast majority of participants with diabetes and hypertension were under treatment, control rates are suboptimal. These findings underscore the need for continued physician's efforts to improve control rates in our population.

\section{Introduction}

The Behavioral Risk Factor Surveillance System (BRFSS) suggests higher prevalence of diabetes mellitus and arterial hypertension among Puerto Rican Hispanics compared to other racial/ethnic groups in the United States (US) [1]. Puerto Ricans show an even higher prevalence of both conditions among Hispanic subgroups living in the US [2,3]. Since both type $2 \mathrm{DM}$ and hypertension are important contributing risk factors for end-organ damage and cardiovascular diseases, management of these conditions is therefore essential for the reduction of associated morbidity and mortality $[4,5]$. Increasing awareness, treatment, and control of these chronic conditions is expected to reduce morbidity and mortality [6-8]. The National Health and Nutrition Examination Survey (NHANES) has demonstrated that despite the documented benefit of blood pressure lowering and glycemic control, rates of detection and control of these conditions have been suboptimal in the US [8]. However, such information is less clear for Hispanic subgroups, especially those living in Puerto Rico. This information is essential for detecting, monitoring and evaluating the quality of care for individuals diagnosed with these conditions.

The present study addressed some of the critical information gaps regarding diabetes and hypertension in a representative sample of the adult population in the San Juan Metropolitan Area (SJMA) of Puerto Rico. The primary aims of the study were to estimate the overall and age- and gender-specific prevalence of pre-hypertension, hypertension, pre-diabetes, and diabetes; determine the percentage of adults with diabetes and hypertension who were aware of their status; determine the percentage of adults diagnosed with these conditions who are under treatment; and determine the percentage of adults with hypertension and diabetes who are under control. The results from this study will provide preliminary data to develop culturally-appropriate interventions which can address improvement of quality of care and reduction of health disparities of these important chronic conditions.

\section{Research Design and Methods}

\section{Study sample}

The study population consisted of a sample of non-institutionalized Puerto Ricans residing in the SJMA. According to the 2010 Census, there were 955,431 inhabitants aged 18 to 79 years in this geographical area that consists of seven municipalities [Carolina $(n=152,396)$, Trujillo Alto $(n=65,732)$, San Juan $(n=347,065)$, Guaynabo $(n=86,746)$, Bayamón $(\mathrm{n}=195,814)$, Toa Baja $(\mathrm{n}=82,418)$, and Cataño $(\mathrm{n}=25,260)]$ [9].

An estimated sample of 452 Puerto Ricans aged 18-79 years residing in the SJMA was selected through a complex, multistage probability sampling design [10-12]. The sampling frame was determined by the

*Corresponding author: Myriam Zaydee Allende-Vigo, Director Endocrinology Section, Medicine PO Box 365067, San Juan, Puerto Rico, USA, Tel: 787-502 1687; Fax: 787-765-9183; E-mail: myriam.allende@upr.edu

Received April 05, 2013; Accepted April 30, 2013; Published May 05, 2013

Citation: Allende-Vigo MZ, Pérez CM, Hernández JJ, Torres CR, Valle $\mathrm{Y}$, et al. (2013) Unequal Burden of Diabetes and Hypertension in the Adult Population of the San Juan Metropolitan Area of Puerto Rico. J Diabetes Metab 4: 261. doi:10.4172/2155-6156.1000261

Copyright: (c) 2013 Allende-Vigo MZ. This is an open-access article distributed under the terms of the Creative Commons Attribution License, which permits unrestricted use, distribution, and reproduction in any medium, provided the original author and source are credited. 
maps of census tracts of the SJMA provided by the Census Bureau, Puerto Rico Planning Board. The statistical information provided by the Census in every tract was divided in groups of blocks of households. A total of 50 groups of blocks were randomly selected in the SJMA using a systematic procedure after ordering the total groups of blocks by the median household value. Afterward, for each selected group of block, one block of households was randomly selected. Then, all the selected blocks were visited to identify the total number of occupied households. Finally, for each household in the selected blocks, all individuals aged 18-79 years were invited to participate in the study. A priori exclusion criteria included pregnant females and subjects who were cognitively or physically impaired. The study was approved by the Institutional Review Board of the University of Puerto Rico Medical Sciences Campus, and written informed consent was given by all participants.

\section{Data collection}

Participants who met eligibility criteria were scheduled to visit the Puerto Rico Clinical and Translational Research Consortium of the University of Puerto Rico-Medical Sciences Campus to undergo the physical evaluation, biochemical measurements, and a face-toface interview. A questionnaire was administered by specially-trained interviewers and covered the following areas: socio-demographic characteristics, lifestyles, medical history, current medication use, and family history of various chronic diseases. Subjects were considered ever smokers if they reported having smoked at least 100 cigarettes during their lifetime. Participants who reported having at least one drink of any type of alcohol during the past 30 days were considered current drinkers. Respondents were classified as meeting national guidelines on physical activity if they reported participation in moderate-intensity activities for a minimum of 30 minutes on five days per week or vigorous-intensity activity for a minimum of 20 minutes on three days per week [13].

\section{Anthropometric and blood pressure measurements}

Weight, height, and waist and hip circumferences were taken in duplicate following the NHANES III Anthropometry Procedures Manual [14], and the average of the two measurements was used. Weight and height were measured to the nearest $0.5 \mathrm{~kg}$ and $0.1 \mathrm{~cm}$, respectively. Body mass index (BMI) categories were defined as underweight $\left(<18.5 \mathrm{~kg} / \mathrm{m}^{2}\right)$, normal $\left(18.5-24.9 \mathrm{~kg} / \mathrm{m}^{2}\right)$, overweight $\left(25.0-29.9 \mathrm{~kg} / \mathrm{m}^{2}\right)$, and obese $\left(\geq 30.0 \mathrm{~kg} / \mathrm{m}^{2}\right)$. Waist circumference was measured using a Gulick 2 Plus measuring tape to the nearest 0.1 $\mathrm{cm}$ at the high point of the iliac crest at minimal respiration when the participant was in a standing position [14]. Hip circumference was measured at the level of greater trochanters and symphisis pubis to the nearest $0.1 \mathrm{~cm}$. Waist to hip ratio was calculated as the ratio of waist $(\mathrm{cm})$ and hip $(\mathrm{cm})$ measures.

Three blood pressure measurements were taken 10 minutes apart using an appropriate cuff size and a standard aneroid sphygmomanometer. Prior to the measurement, participants were asked to seat quietly in a chair for at least five minutes, with feet on the floor and arm supported at the chest level. Blood pressure status was based on the average of the three measurements.

\section{Biochemical assays}

Blood samples were drawn in the morning after at least a 10-hour fast. Fasting blood samples $(5 \mathrm{~mL})$ were drawn for determination of fasting plasma lipids, chemical comprehensive metabolic panel, and hemoglobin Alc using standard assays: microalbumin/creatinine in urine and hemoglobin A1c in blood were collected using the DCA quantitative assays (Siemens Healthcare Diagnostics Inc., Tarrytown,

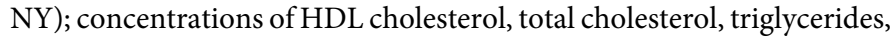
and fasting plasma glucose were collected using Vitros' colorimetric kits (Ortho-Clinical Diagnostics, Inc., Rochester, NY); and high sensitive CRP was collected using the immunoturbidimetric method (Roche Diagnostics Corporation, Hague Rd, IN).

\section{Definitions of study outcomes}

Prevalent diabetes was defined based on fasting plasma glucose levels of at least $126 \mathrm{mg} / \mathrm{dL}, \mathrm{HbAlc}$ of at least $6.5 \%$, or both, and/ or reported current use of prescribed anti-diabetic medications [4]. Prevalent pre-diabetes included subjects who did not self-report diabetes but had HbAlc levels between $5.7 \%$ and $6.4 \%$, fasting blood glucose between $100 \mathrm{mg} / \mathrm{dL}$ and $125 \mathrm{mg} / \mathrm{dL}$ or both [4]. Diabetes awareness was determined based on those participants who responded "yes" to the question "Have you ever told by a doctor that you have diabetes?". Diabetes was considered under treatment if participants responded "yes" to the question "Have you ever told by a doctor that you have diabetes" and were taking prescribed anti-diabetic medications, including insulin. Diabetes was considered to be under control in subjects under treatment if HbAlc levels were below 7\% [4].

Prevalent hypertension was defined as mean systolic blood pressure levels of at least $140 \mathrm{~mm} \mathrm{Hg}$, mean diastolic blood pressure of at least $90 \mathrm{~mm} \mathrm{Hg}$, or both, and/or reported current use of prescribed antihypertensive medications [6]. Prevalent pre-hypertension was defined as a participant who did not report hypertension, and had mean systolic blood pressure between $120 \mathrm{~mm} \mathrm{Hg}$ and $139 \mathrm{~mm} \mathrm{Hg}$ or a mean diastolic blood pressure between $80 \mathrm{~mm} \mathrm{Hg}$ and $89 \mathrm{~mm} \mathrm{Hg}$ [6]. Hypertension awareness was determined based on those participants who responded "yes" to the question "Have you ever told by a doctor that you have hypertension?". Hypertension was considered under treatment if participants responded "yes" to the question "Have you ever told by a doctor that you have hypertension" and self-reported taking prescribed antihypertensive medications. For participants that had not been diagnosed with diabetes, hypertension was considered to be under control in subjects on treatment if the average blood pressure was below 140/90 mm Hg. For participants diagnosed with diabetes, hypertension was considered to be under control in subjects under treatment if the average blood pressure was below 130/80 mm Hg.

\section{Statistical analysis}

Prevalence of diabetes, prediabetes, hypertension, and prehypertension (overall and age- and gender specific) was estimated using a logistic regression model. In order to get an unbiased estimator of the prevalence, a weighting factor was considered in this model to control the effect of the sampling design. This weighting factor was normalized using the following expression:

$$
w_{i}=\frac{1 /\left(f_{1} * f_{2} * f_{3}\right)}{\bar{w}}
$$

where $f_{1}$ was the selection probability for each participant, $f_{2}$ was the rate of participation in each block, $\mathrm{f}_{3}$ was the post-stratification adjustment based on the age and gender distribution of the Census 2010 in the SJMA, and $\bar{w}$ was the mean final weight for the entire sample [10]. Data management and all statistical analyses were performed using the statistical package Stata (Version 11.0, College Station, TX, USA). 
Citation: Allende-Vigo MZ, Pérez CM, Hernández JJ, Torres CR, Valle Y, et al. (2013) Unequal Burden of Diabetes and Hypertension in the Adult Population of the San Juan Metropolitan Area of Puerto Rico. J Diabetes Metab 4: 261. doi:10.4172/2155-6156.1000261

Page 3 of 7

\section{Results}

Of the selected residents, $452(63 \%)$ consented to participate in the face-to-face interview and provided blood and urine samples suitable for analyses. The gender distribution of the sample (female: $59.1 \%$; males: $40.9 \%$ ) was similar to that of the adult population of the SJMA of Puerto Rico according to the Census 2010 (female: 54.1\%; males: 45.9\%) (Table 1). However, the age distribution of the sample was different to that of the SJMA of Puerto Rico (sample: $18-44$ years: $39.4 \%$; $45-64$ years: $39.4 \%$; $65-79$ years: $21.2 \%$ vs. Census: $49.5 \%, 34.5 \%, 16.0 \%$, respectively).

The majority of women were aged 45-64 years, whereas most males were aged 18-44 years. Most of the participants had at least 12 years of education, and approximately $60 \%$ of the participants reported a family annual income below $\$ 20,000$. Around $33 \%$ of the participants reported public health insurance, with a larger proportion among females. Lifetime smoking exposure was more frequent among women than among males (68.4\% vs. $48.1 \%)$. Nearly $79 \%$ of adults were overweight $(34.7 \%)$ or obese $(43.8 \%)$, with no significant differences in gender. A significant higher proportion of women reported meeting physical activity recommendations, and had elevated waist circumference, waist-to-hip ratio, and hs-CRP. However, a higher proportion of men exhibited reduced HDL-cholesterol, and elevated triglycerides, AST and ALT levels.

\section{Prevalence of diabetes, prediabetes, hypertension and pre- hypertension}

Overall prevalence of diabetes was $15.2 \%$ (95\% CI: $11.9 \%, 18.5 \%)$, corresponding to 119,300 adults (95\% CI: $93,000,144,800)$ in the SJMA of Puerto Rico (Table 2). The overall prevalence of diabetes increased with age in both genders, from $2.5 \%$ in the age group 18-44 years to $35.6 \%$ among those aged $65-79$ years. Males aged $18-64$ years were more likely than females of the same age group to have diabetes (31.9\% versus $22.1 \%$ ), whereas females 65 years and older had a higher prevalence of diabetes compared to their male counterparts $(47.9 \%$ versus $18.9 \%)$.

On the other hand, the overall prevalence of pre-diabetes was $35.3 \%$ (95\% CI: $30.9 \%, 39.7 \%$ ), corresponding to 275,800 (95\% CI $241,750,310,600)$ adults with pre-diabetes. This prevalence also increased markedly with age in both genders and reached the peak at age 65-79 years (64.8\%). Prevalence of prehypertension was higher among women aged 65-79 compared to their male counterparts $(81.8 \%$ versus $41.7 \%)$.

\begin{tabular}{|c|c|c|c|c|c|c|}
\hline \multirow{2}{*}{ Characteristics } & \multicolumn{2}{|c|}{ Total $(n=452)$} & \multicolumn{2}{|c|}{ Women $(n=267)$} & \multicolumn{2}{|c|}{ Male $(n=185)$} \\
\hline & Frequency & $\%$ & Frequency & $\%$ & Frequency & $\%$ \\
\hline \multicolumn{7}{|l|}{ Age (years) } \\
\hline $18-44$ & 178 & 39.4 & 99 & 37.1 & 79 & 42.7 \\
\hline $45-64$ & 178 & 39.4 & 108 & 40.4 & 70 & 37.8 \\
\hline $65-79$ & 96 & 21.2 & 60 & 22.5 & 36 & 19.5 \\
\hline \multicolumn{7}{|l|}{ Education (years) } \\
\hline$\leq 8$ & 56 & 12.4 & 34 & 12.8 & 22 & 11.9 \\
\hline $9-12$ & 167 & 37.0 & 88 & 33.1 & 79 & 42.7 \\
\hline$\geq 12$ & 228 & 50.6 & 144 & 54.1 & 84 & 45.4 \\
\hline \multicolumn{7}{|l|}{ Marital status } \\
\hline Single & 108 & 23.9 & 68 & 25.6 & 40 & 21.6 \\
\hline Married & 178 & 39.5 & 97 & 36.4 & 81 & 43.8 \\
\hline Other & 165 & 36.6 & 101 & 38.0 & 64 & 34.6 \\
\hline \multicolumn{7}{|l|}{ Annual family income } \\
\hline$<\$ 20,000$ & 259 & 57.4 & 154 & 57.9 & 105 & 56.8 \\
\hline$\$ 20,000-\$ 50,000$ & 122 & 27.1 & 70 & 26.3 & 52 & 28.1 \\
\hline$>\$ 50,000$ & 25 & 5.5 & 13 & 4.9 & 12 & 6.5 \\
\hline \multicolumn{7}{|l|}{ Primary medical insurance ${ }^{*}$} \\
\hline Public & 147 & 32.6 & 97 & 36.5 & 50 & 27.0 \\
\hline Private & 252 & 55.9 & 148 & 55.6 & 104 & 56.2 \\
\hline None & 52 & 11.5 & 21 & 7.9 & 31 & 16.8 \\
\hline \multicolumn{7}{|l|}{ Smoking status* } \\
\hline Yes & 271 & 60.1 & 182 & 68.4 & 89 & 48.4 \\
\hline No & 179 & 39.7 & 84 & 31.6 & 95 & 51.6 \\
\hline \multicolumn{7}{|l|}{ Perceived health status } \\
\hline Excellent & 51 & 11.3 & 25 & 9.4 & 26 & 14.1 \\
\hline Very good & 47 & 10.4 & 26 & 9.8 & 21 & 11.3 \\
\hline Good & 170 & 37.7 & 104 & 39.1 & 66 & 35.7 \\
\hline Regular & 162 & 35.9 & 96 & 36.1 & 66 & 35.7 \\
\hline Poor & 21 & 4.7 & 15 & 5.6 & 6 & 3.2 \\
\hline \multicolumn{7}{|l|}{ BMI $\left(\mathrm{kg} / \mathrm{m}^{2}\right)$} \\
\hline$<18.5$ & 10 & 2.2 & 9 & 3.4 & 1 & 0.5 \\
\hline $18.5-24.9$ & 87 & 19.3 & 47 & 17.7 & 40 & 21.6 \\
\hline $25.0-29.9$ & 156 & 34.7 & 90 & 34.0 & 66 & 35.7 \\
\hline$\geq 30.0$ & 197 & 43.8 & 119 & 44.9 & 78 & 42.2 \\
\hline
\end{tabular}


Citation: Allende-Vigo MZ, Pérez CM, Hernández JJ, Torres CR, Valle Y, et al. (2013) Unequal Burden of Diabetes and Hypertension in the Adult Population of the San Juan Metropolitan Area of Puerto Rico. J Diabetes Metab 4: 261. doi:10.4172/2155-6156.1000261

Page 4 of 7

\begin{tabular}{|c|c|c|c|c|c|c|}
\hline Yes & 140 & 31.0 & 86 & 32.3 & 54 & 29.2 \\
\hline No & 311 & 69.0 & 180 & 67.7 & 131 & 70.8 \\
\hline \multicolumn{7}{|l|}{ Physical activity* } \\
\hline Yes & 139 & 30.7 & 93 & 34.8 & 46 & 24.9 \\
\hline No & 313 & 69.3 & 174 & 65.2 & 139 & 75.1 \\
\hline \multicolumn{7}{|l|}{ Waist Circumference* } \\
\hline $\begin{array}{c}\text { Normal } \\
\text { (women: <35", men: <40") }\end{array}$ & 228 & 50.4 & 106 & 39.7 & 122 & 65.9 \\
\hline $\begin{array}{c}\text { Elevated } \\
\text { (women: } \geq 35 ", \text { men: } \geq 40 \text { ") }\end{array}$ & 224 & 49.6 & 161 & 60.3 & 63 & 34.1 \\
\hline \multicolumn{7}{|l|}{ Waist to Hip Ratio* Eliminate (cm) } \\
\hline $\begin{array}{c}\text { Normal } \\
\text { (women: } \leq 0.8, \text { men: } \leq 0.9 \text { ) }\end{array}$ & 117 & 25.9 & 52 & 19.5 & 65 & 35.1 \\
\hline $\begin{array}{c}\text { Elevated } \\
\text { (women: }>0.8, \text { men: }>0.9)\end{array}$ & 335 & 74.1 & 215 & 80.5 & 120 & 64.9 \\
\hline \multicolumn{7}{|l|}{ Blood Pressure* } \\
\hline$<120 / 80$ & 199 & 44.2 & 133 & 50.2 & 66 & 35.7 \\
\hline $120-139 / 80-89$ & 151 & 33.6 & 69 & 26.0 & 82 & 44.3 \\
\hline $140-159 / 90-99$ & 74 & 16.4 & 44 & 16.6 & 30 & 16.2 \\
\hline$\geq 160 / 100$ & 26 & 5.8 & 19 & 7.2 & 7 & 3.8 \\
\hline \multicolumn{7}{|l|}{ Blood Glucose (mmol/L) } \\
\hline$<5.6$ & 340 & 75.4 & 205 & 77.1 & 135 & 73.0 \\
\hline $5.6-6.9$ & 71 & 15.7 & 36 & 13.5 & 35 & 18.9 \\
\hline$\geq 7.0$ & 40 & 8.9 & 25 & 9.4 & 15 & 8.1 \\
\hline \multicolumn{7}{|l|}{ HbA1c (\%) } \\
\hline$<5.7$ & 184 & 40.8 & 96 & 36.1 & 88 & 47.6 \\
\hline $5.7-6.4$ & 218 & 48.3 & 140 & 52.6 & 78 & 42.1 \\
\hline$\geq 6.5$ & 49 & 10.9 & 30 & 11.3 & 19 & 10.3 \\
\hline \multicolumn{7}{|l|}{ Total Cholesterol (mmol/L) } \\
\hline$<5.2$ & 303 & 67.2 & 170 & 63.9 & 133 & 71.9 \\
\hline $5.2-6.1$ & 101 & 22.4 & 62 & 23.3 & 39 & 21.1 \\
\hline$\geq 6.2$ & 47 & 10.4 & 34 & 12.8 & 13 & 7.0 \\
\hline \multicolumn{7}{|l|}{$\mathrm{HDL}-\mathrm{C}^{\star}(\mathrm{mmol} / \mathrm{L})$} \\
\hline$<1.0$ & 111 & 24.6 & 45 & 16.9 & 66 & 35.7 \\
\hline $1.0-1.5$ & 274 & 60.8 & 171 & 64.3 & 103 & 55.7 \\
\hline$\geq 1.6$ & 66 & 14.6 & 50 & 18.8 & 16 & 8.6 \\
\hline \multicolumn{7}{|l|}{ Triglycerides* $(\mathrm{mmol} / \mathrm{L})$} \\
\hline$<1.7$ & 297 & 65.9 & 187 & 70.3 & 110 & 59.5 \\
\hline $1.7-2.2$ & 80 & 17.7 & 45 & 16.9 & 35 & 18.9 \\
\hline $2.3-5.6$ & 68 & 15.1 & 33 & 12.4 & 35 & 18.9 \\
\hline$\geq 5.7$ & 6 & 1.3 & 1 & 0.4 & 5 & 2.7 \\
\hline \multicolumn{7}{|l|}{ Albumin-creatinine ratio $(\mathrm{mg} / \mathrm{G})$} \\
\hline$<30$ & 389 & 87.4 & 233 & 89.3 & 156 & 84.8 \\
\hline $30-299$ & 54 & 12.1 & 27 & 10.3 & 27 & 14.7 \\
\hline$\geq 300$ & 2 & 0.5 & 1 & 0.4 & 1 & 0.5 \\
\hline \multicolumn{7}{|l|}{$\mathrm{CRP}^{*}(\mathrm{mg} / \mathrm{L})$} \\
\hline$<1.0$ & 153 & 33.9 & 74 & 27.8 & 79 & 42.7 \\
\hline $1.0-3.0$ & 137 & 30.4 & 73 & 27.5 & 64 & 34.6 \\
\hline $3.1-10.0$ & 121 & 26.8 & 87 & 32.7 & 34 & 18.4 \\
\hline$\geq 10.1$ & 40 & 8.9 & 32 & 12.0 & 8 & 4.3 \\
\hline \multicolumn{7}{|l|}{$\mathrm{AST}^{\star}(\mathrm{U} / \mathrm{L})$} \\
\hline$<15.0$ & 59 & 13.1 & 44 & 16.5 & 15 & 8.1 \\
\hline $15.0-46.0$ & 345 & 76.5 & 197 & 74.1 & 148 & 80.0 \\
\hline$>46.0$ & 47 & 10.4 & 25 & 9.4 & 22 & 11.9 \\
\hline \multicolumn{7}{|l|}{$\operatorname{ALT}^{*}(\mathrm{U} / \mathrm{L})$} \\
\hline$<11.0$ & 50 & 11.1 & 39 & 14.6 & 11 & 6.0 \\
\hline $11.0-66.0$ & 380 & 84.3 & 222 & 83.5 & 158 & 85.4 \\
\hline$>66.0$ & 21 & 4.6 & 5 & 1.9 & 16 & 8.6 \\
\hline
\end{tabular}

${ }^{*} \mathrm{P}$ value for gender differences $<0.05$

Table 1: Baseline characteristics of participants by sex in the SJMA, Puerto Rico. 
Citation: Allende-Vigo MZ, Pérez CM, Hernández JJ, Torres CR, Valle Y, et al. (2013) Unequal Burden of Diabetes and Hypertension in the Adult Population of the San Juan Metropolitan Area of Puerto Rico. J Diabetes Metab 4: 261. doi:10.4172/2155-6156.1000261

Page 5 of 7

Overall prevalence of hypertension was $39.9 \%$ (95\% CI: $35.4 \%$, $44.4 \%$ ), corresponding to 312,250 (95\% CI: 276,900, 347,450) adults with hypertension in this geographical area of Puerto Rico. The overall prevalence of pre-hypertension was $44.9 \%$ (95\% CI: 40.3\%, 49.5\%), corresponding to 351,400 (95\% CI: 315,350, 387,200) adults with prehypertension. The prevalence of both conditions increased steeply from 18-44 years onwards reaching a peak at age 65-79 years for both genders. Although there were no marked differences in the age-specific prevalence of hypertension by gender, prevalence of prehypertension was higher in men across all age groups.

\section{Distribution of co-morbidities among subjects with diabetes and hypertension}

Almost three-quarters of the participants with diabetes reported hypertension (74.4\%), over half reported hypercholesterolemia (53.7\%), and 39\% reported hypertriglyceridemia (39\%) (data not shown). A significant number of participants with a diagnosis of hypertension were also diagnosed with diabetes (68.2\%), hypercholesterolemia (47.9\%) or hypertriglyceridemia (31.8\%). Among those with a diagnosis of diabetes, $80.5 \%$ reported to have three or more comorbidities. However, among those with a diagnosis of hypertension, $62.0 \%$ reported to have at least three co-morbidities.

\section{Percentage of participants under treatment and control}

More than $75 \%$ of participants with diabetes and hypertension were aware of their diagnosis (78.6\% and $81.5 \%$, respectively) (Table 3). The overwhelming majority of participants diagnosed with diabetes and hypertension were under treatment $(90.9 \%$ and $91.6 \%$, respectively). Notwithstanding, only $35 \%$ of those diagnosed with diabetes and $52.5 \%$ of those diagnosed with hypertension were controlled on pharmacotherapy. Despite the limited sample sizes, there were no marked variations in the percentages of adults with diabetes and hypertension who were aware, treated and controlled by gender.

\section{Conclusion}

These analyses provide up-to-date estimates of the prevalence diabetes, prediabetes, hypertension and prehypertension among adults aged 18-79 living in the SJMA of Puerto Rico. In addition, we assessed the levels of awareness, treatment, and control among adults with diabetes and hypertension. We found that nearly $15.2 \%$ of adults have diabetes and $35.3 \%$ to have pre-diabetes, estimates that are higher than those reported by BRFSS in 2010 ( $12.8 \%$ and $8.6 \%$, respectively) [1]. As expected, prevalence of both diabetes and pre-diabetes increased significantly with age, finding that is consistent with previous studies in Puerto Rico $[15,16]$. The findings of this study support the notion that the burden of DM and prediabetes in Puerto Rico is significant $[2,3,17]$

\begin{tabular}{|c|c|c|c|c|c|c|}
\hline & \multicolumn{2}{|r|}{ Total } & \multicolumn{2}{|r|}{ Men } & \multicolumn{2}{|r|}{ Women } \\
\hline & Percent & $\begin{array}{l}\text { Estimated population } \\
\qquad(95 \% \mathrm{Cl})\end{array}$ & Percent & $\begin{array}{l}\text { Estimated population } \\
(95 \% \mathrm{Cl})\end{array}$ & Percent & $\begin{array}{c}\text { Estimated population } \\
(95 \% \mathrm{Cl})\end{array}$ \\
\hline \multicolumn{7}{|l|}{ Diabetes } \\
\hline $18-79$ years & 15.2 & $\begin{array}{c}119,300 \\
(93,000-144,800)\end{array}$ & 15.8 & $\begin{array}{c}51,200 \\
(37,750-75,800)\end{array}$ & 16.1 & $\begin{array}{c}68,100 \\
(48,650-85,850)\end{array}$ \\
\hline 18-44 years & 2.5 & $\begin{array}{c}9,750 \\
(800-18,550)\end{array}$ & 4.5 & $\begin{array}{c}8,300 \\
(2,200-28,800)\end{array}$ & 0.73 & $\begin{array}{c}1,450 \\
(350-6,300)\end{array}$ \\
\hline $45-64$ years & 24.1 & $\begin{array}{c}64,950 \\
(48,100-82,000)\end{array}$ & 27.4 & $\begin{array}{c}32,850 \\
(18,650-52,250)\end{array}$ & 21.4 & $\begin{array}{c}32,100 \\
(19,850-49,100)\end{array}$ \\
\hline $65-79$ years & 35.6 & $\begin{array}{c}44,600 \\
(32,600-56,550)\end{array}$ & 18.9 & $\begin{array}{c}10,050 \\
(3,100-24,850)\end{array}$ & 47.9 & $\begin{array}{c}34,550 \\
(14,750-55,350)\end{array}$ \\
\hline \multicolumn{7}{|l|}{ Pre-diabetes } \\
\hline $18-79$ years & 35.3 & $\begin{array}{c}275,800 \\
(241,750-310,600)\end{array}$ & 30.8 & $\begin{array}{c}110,200 \\
(86,600-134,750)\end{array}$ & 39.1 & $\begin{array}{c}165,600 \\
(140,450-189,950)\end{array}$ \\
\hline $18-44$ years & 9.8 & $\begin{array}{c}38,100 \\
(20,900-55,000)\end{array}$ & 7.6 & $\begin{array}{c}14,150 \\
(5,750-32,550)\end{array}$ & 11.9 & $\begin{array}{c}23,950 \\
(11,800-45,700)\end{array}$ \\
\hline $45-64$ years & 58.0 & $\begin{array}{c}156,550 \\
(136,850-176,300)\end{array}$ & 61.7 & $\begin{array}{c}73,900 \\
(38,600-101,200)\end{array}$ & 55.0 & $\begin{array}{c}82,650 \\
(60,550-103,500)\end{array}$ \\
\hline $65-79$ years & 64.8 & $\begin{array}{c}81,150 \\
(69,100-93,150)\end{array}$ & 41.7 & $\begin{array}{c}22,150 \\
(6,250-42,050)\end{array}$ & 81.8 & $\begin{array}{c}59,000 \\
(42,000-67,500)\end{array}$ \\
\hline \multicolumn{7}{|l|}{ Hypertension } \\
\hline $18-79$ years & 39.9 & $\begin{array}{c}312,250 \\
(276,900-347,450)\end{array}$ & 37.6 & $\begin{array}{c}135,050 \\
(110,050-160,200)\end{array}$ & 41.9 & $\begin{array}{c}177,200 \\
(129,300-171,800)\end{array}$ \\
\hline $18-44$ years & 14.2 & $\begin{array}{c}55,150 \\
(35,100-74,850)\end{array}$ & 12.3 & $\begin{array}{c}23,050 \\
(7,750-58,750)\end{array}$ & 16.0 & $\begin{array}{c}32,100 \\
(14,900-62,500)\end{array}$ \\
\hline $45-64$ years & 54.7 & $\begin{array}{c}147,650 \\
(127,950-167,400)\end{array}$ & 56.5 & $\begin{array}{c}67,650 \\
(42,700-90,100)\end{array}$ & 53.2 & $\begin{array}{c}80,000 \\
(62,750-96,750)\end{array}$ \\
\hline $65-79$ years & 87.4 & $\begin{array}{c}109,450 \\
(101,150-117,750)\end{array}$ & 83.6 & $\begin{array}{c}44,350 \\
(28,800-50,700)\end{array}$ & 90.2 & $\begin{array}{c}65,100 \\
(50,700-70,200)\end{array}$ \\
\hline \multicolumn{7}{|l|}{ Pre-hypertension } \\
\hline $18-79$ years & 44.9 & $\begin{array}{c}351,400 \\
(315,350-387,200)\end{array}$ & 53.9 & $\begin{array}{c}193,600 \\
(167,900-219,481)\end{array}$ & 37.3 & $\begin{array}{c}157,800 \\
(133,250-182,300)\end{array}$ \\
\hline $18-44$ years & 31.0 & $\begin{array}{c}120,100 \\
(93,750-146,300)\end{array}$ & 43.1 & $\begin{array}{c}80,350 \\
(48,150-116,050)\end{array}$ & 19.8 & $\begin{array}{c}39,750 \\
(16,950-79,800)\end{array}$ \\
\hline 45-64 years & 59.8 & $\begin{array}{c}161,300 \\
(142,000-180,850)\end{array}$ & 66.0 & $\begin{array}{c}79,000 \\
(50,400-100,350)\end{array}$ & 54.8 & $\begin{array}{c}82,300 \\
(41,400-119,300)\end{array}$ \\
\hline $65-79$ years & 55.9 & $\begin{array}{c}70,000 \\
(57,550-82,450)\end{array}$ & 64.5 & $\begin{array}{c}34,250 \\
(12,700-48,450)\end{array}$ & 49.5 & $\begin{array}{c}35,750 \\
(16,700-54,950)\end{array}$ \\
\hline
\end{tabular}

Table 2: Prevalence of diabetes, pre-diabetes, hypertension and pre-hypertension in the adult population of the San Juan Metropolitan Area of Puerto Rico. 
Citation: Allende-Vigo MZ, Pérez CM, Hernández JJ, Torres CR, Valle Y, et al. (2013) Unequal Burden of Diabetes and Hypertension in the Adult Population of the San Juan Metropolitan Area of Puerto Rico. J Diabetes Metab 4: 261. doi:10.4172/2155-6156.1000261

Page 6 of 7

\begin{tabular}{|c|c|c|c|c|c|c|}
\hline & \multicolumn{3}{|c|}{ Men } & \multicolumn{3}{|c|}{ Women } \\
\hline & Aware n (\%) & Treated n (\%) & Controlled n (\%) & Aware n (\%) & Treated n (\%) & Controlled n (\%) \\
\hline Diabetes & $30(76.9)$ & $26(86.7)$ & $13(50.0)$ & $36(80.0)$ & $34(94.4)$ & $8(23.5)$ \\
\hline Hypertension & $58(82.9)$ & $50(86.2)$ & $26(52.0)$ & $96(80.7)$ & $91(94.8)$ & $48(52.7)$ \\
\hline
\end{tabular}

Table 3: Percentage of adults aged 18-79 with diabetes and hypertension who are aware, treated, and controlled in the San Juan Metropolitan Area of Puerto Rico .

Our findings are consistent with other studies showing that the prevalence of hypertension is higher in the Hispanic population in the US [18-20]. We found a prevalence of hypertension and pre-hypertension of $39.9 \%$ and $44.9 \%$, respectively. Prevalence of hypertension was higher than that reported in the 2010 BRFSS data in Puerto Rico (34.0\%) [1]. Prevalence of hypertension and prehypertension increased with age in both genders and pre-hypertension was more prevalent among males in all age groups. In the 2000-2005 National Health Survey Interview Survey, it was found that Puerto Ricans had a higher prevalence of diabetes and hypertension compared to other Hispanic sub-groups [2]. Participants in our study with both diabetes and hypertension were older, had a lower income and less formal education, findings in accordance with previous reports [2,15-17]. Similar to other studies, participants with diabetes and obesity had a significantly higher prevalence of hypertension than those without diabetes.

Ong et al. reported that the rate of awareness, treatment and control of hypertension in US did not increase from 2000 to 2004 [18]. However, recent data indicate that the age-adjusted prevalence of hypertension in the US has remained unchanged (29.9\% for the period 2005-2008), but the control rates have improved to $50.1 \%$ [8]. This analysis also revealed that rates of uncontrolled hypertension were higher among those classified as obese and those with diabetes. Although we found that the vast majority of participants in our study with diabetes and hypertension were under treatment, control rates were suboptimal. Only $35 \%$ of those diagnosed with diabetes and $52.5 \%$ of those diagnosed with hypertension were controlled on pharmacotherapy, findings consistent with previous studies. Cooper et al. reported that African Americans are disproportionately affected by hypertension and its complications, and several barriers affect the effective blood pressure control [20]. In our study population of Hispanics the burden of hypertension is higher than in mainland Caucasians, and most of our subjects had uncontrolled hypertension. Potential barriers to control include low socioeconomic status, financial difficulties, higher costs of medication, low health literacy, and unemployment [20].

Individuals with both diabetes and hypertension also had higher mean levels of BMI and waist circumference. In this study, $78 \%$ of study participants were overweight or obese (34.7\% overweight and $43.8 \%$ obese), a figure higher than the BFRSS combined self-reported estimate for 2010 (38.1\% overweight and $27.5 \%$ obese) [21]. This estimate was also higher than the most recent NHANES estimate for overweight and obesity $(68.0 \%$ for all adults $\geq 20$ years); however, it was similar to the estimate reported for all Hispanics (77.9\%) [21]. In addition to general and abdominal obesity, study participants with diabetes and hypertension also had more co-morbidities including elevated blood lipids, conditions that increase their cardio-metabolic risk.

Strengths of our study include that the sample was representative of the adult population living in the San Juan metropolitan area and that the response rate was adequate. Amongst the limitations are that findings cannot be generalized to the entire population of Puerto Rico, and the small number of subjects with either diabetes or hypertension precluded the assessment of awareness, treatment and control of these conditions across sociodemographic and clinical characteristics.
The study findings underscore the unequal burden of diabetes, prediabetes, hypertension, and prehypertension in a Hispanic subgroup, placing this population at a higher cardiometabolic risk. The study findings also underscore the need for continued physician's efforts to improve control rates in our population. Such information may be helpful to health care decision makers. Future research should address the burden of these conditions in a broader representative sample in Puerto Rico.

\section{Acknowledgments}

This project was funded by an unrestricted grant from Novartis Pharmaceuticals with additional support from the National Institutes of Health grant awards U54 RR026139 and U54-MD007587 to the Puerto Rico Clinical and Translational Research Consortium at the University of Puerto Rico. No potential conflicts of interest relevant to this article were reported.

MZAV, CMP, JJH and ES participated in the design concept of the study. MZAV, CMP, CRT, YV and RR participated in acquisition of data. ES and CRT participated in the data analysis, and ES, CMP, and MZAV researched and interpreted the data and drafted the manuscript. JJH contributed to interpretation of data and discussion. All authors reviewed, commented on, and approved the final manuscript.

\section{References}

1. Centers for Disease Control and Prevention (2013) Behavioral Risk Factor Surveillance System Survey Data. Atlanta, Georgia: U.S. Department of Health and Human Services, Centers for Disease Control and Prevention, 2000-2010.

2. Pabon-Nau LP, Cohen A, Meigs JB, Grant RW (2010) Hypertension and diabetes prevalence among U.S. Hispanics by country of origin: the National Health Interview Survey 2000-2005. J Gen Intern Med 25: 847-852.

3. Daviglus ML, Talavera GA, Avilés-Santa ML, Allison M, Cai J, et al. (2012) Prevalence of major cardiovascular risk factors and cardiovascular diseases among Hispanic/Latino individuals of diverse backgrounds in the United States. JAMA 308: 1775-1784

4. American Diabetes Association (2013) Standards of medical care in diabetes--2013. Diabetes Care 36: S11-66.

5. National Cholesterol Education Program (NCEP) Expert Panel on Detection Evaluation, and Treatment of High Blood Cholesterol in Adults (Adult Treatment Panel III) (2002) Third Report of the National Cholesterol Education Program (NCEP) Expert Panel on Detection, Evaluation, and Treatment of High Blood Cholesterol in Adults (Adult Treatment Panel III) final report. Circulation 106 3143-3421.

6. Grundy SM, Cleeman JI, Merz CN, Brewer HB Jr, Clark LT, et al. (2004) Implications of recent clinical trials for the National Cholesterol Education Program Adult Treatment Panel III guidelines. Circulation 110: 227-239.

7. Chobanian AV, Bakris GL, Black HR, Cushman WC, Green LA, et al. (2003) Seventh report of the Joint National Committee on Prevention, Detection, Evaluation, and Treatment of High Blood Pressure. Hypertension 42: 12061252

8. Egan BM, Zhao Y, Axon RN (2010) US trends in prevalence, awareness treatment, and control of hypertension, 1988-2008. JAMA 303: 2043-2050.

9. U.S. Census Bureau (2010) 2010 Census Summary File 1

10. Heeringa SG, West BT, Berglund PA (2010) Applied Survey Data Analysis Boca Raton, FL: Chapman \& Hall/CRC, 2010

11. Kish L (1967) Survey sampling. New York: John Wiley \& Sons, Inc.

12. Pan W (2001) Sample size and power calculations with correlated binary data Control Clin Trials 22: 211-227.

13. Haskell WL, Lee IM, Pate RR, Powell KE, Blair SN, et al. (2007) Physical activity and public health: Updated recommendation for adults from the 
Citation: Allende-Vigo MZ, Pérez CM, Hernández JJ, Torres CR, Valle Y, et al. (2013) Unequal Burden of Diabetes and Hypertension in the Adult Population of the San Juan Metropolitan Area of Puerto Rico. J Diabetes Metab 4: 261. doi:10.4172/2155-6156.1000261

American College of Sports Medicine and the American Heart Association. Med Sci Sports Exerc 39: 1423-1434.

14. Centers for Disease Control and Prevention, National Center for Health Statistics. National Health and Nutrition Examination Survey (NHANES) Anthropometry Procedures Manual.

15. Pérez-Cardona C, Pérez-Perdomo R (2001) Prevalence and associated factors of diabetes mellitus in Puerto Rican adults: behavioral risk factor surveillance system, 1999. P R Health Sci J 20: 147-155.

16. Pérez-Perdomo R, Pérez-Cardona CM, Disdier-Flores OM (2003) Health disparities between diabetic patients under private and public health coverage in Puerto Rico, 2000. P R Health Sci J 22: 363-368.

17. Centers for Disease Control and Prevention (CDC) (2008) State-specific incidence of diabetes among adults--participating states, 1995-1997 and 20052007. MMWR Morb Mortal Wkly Rep 57: 1169-1173.

18. Ong KL, Cheung BM, Man YB, Lau CP, Lam KS (2007) Prevalence, awareness treatment, and control of hypertension among United States adults 1999-2004. Hypertension 49: 69-75.

19. Keenan NL, Rosendorf KA; Centers for Disease Control and Prevention (CDC) (2011) Prevalence of hypertension and controlled hypertension - United States 2005-2008. MMWR Surveill Summ 60 Suppl: 94-97.

20. Cooper LA (2009) A 41-year-old African American man with poorly controlled hypertension: review of patient and physician factors related to hypertension treatment adherence. JAMA 301: 1260-1272.

21. Flegal KM, Carroll MD, Ogden CL, Curtin LR (2010) Prevalence and trends in obesity among US adults, 1999-2008. JAMA 303: 235-241. 